\title{
Evaluating hazard results for Switzerland and how not to do it: A discussion of "Problems in the application of the SSHAC probability method for assessing earthquake hazards at Swiss nuclear power plants" by J-U Klügel
}

R.M.W. Musson', G.R. Toro ${ }^{2}$, K.J. Coppersmith ${ }^{3}$, J.J. Bommer ${ }^{4}$, N. Deichmann $^{5}$, H. Bungum ${ }^{6}$, F. Cotton ${ }^{7}$, F. Scherbaum ${ }^{8}$, D. Slejko, ${ }^{9}$ and N.A. Abrahamson ${ }^{10}$.

1. British Geological Survey, West Mains Road, Edinburgh EH9 3LA, UK 2. Risk Engineering, Inc., 3 Farmers Row, Acton, MA 01720 USA

3. Coppersmith Consulting, Inc., 2121 N. California St., Suite 290, Walnut Creek, CA, 94596, USA

4. Dept. Civil and Environmental Engineering, Imperial College, London, South Kensington Campus, London SW7 2AZ, UK

5. Swiss Seismological Service, Institute of Geophysics, ETH Hoenggerberg, $\mathrm{CH}-8093$ Zurich, Switzerland

6. NORSAR, Kjeller, Norway

7. Laboratoire de Géophysique Interne et Tectonophysique, Université Joseph Fourier, BP 53, 38041 Grenoble cedex 9, France

8. Institut für Geowissenschaften, Universität Potsdam, Postfach 601553, D14415 Potsdam, Germany

9. Istituto Nazionale di Oceanografia e di Geofisica Sperimentale Borgo Grotta Gigante 42c, 34010 Sgonico (Trieste), Italy

10. Pacific Gas \& Electric Company, San Francisco, CA, USA

\section{Abstract}

The PEGASOS project was a major international seismic hazard study, one of the largest ever conducted anywhere in the world, to assess seismic hazard at four nuclear power plant sites in Switzerland. Before the report of this project has become publicly available, a paper attacking both methodology and results has appeared. Since the general scientific readership may have difficulty in assessing this attack in 
the absence of the report being attacked, we supply a response in the present paper. The bulk of the attack, besides some misconceived arguments about the role of uncertainties in seismic hazard analysis, is carried by some exercises that purport to be validation exercises. In practice, they are no such thing; they are merely independent sets of hazard calculations based on varying assumptions and procedures, often rather questionable, which come up with various different answers which have no particular significance.

\section{Keywords}

Seismic hazard analysis, epistemic uncertainty, aleatory variability, hazard methodology, validation, PEGASOS, strong ground motion, ground-motion prediction

\section{Introduction}

The publication of the paper "Problems in the application of the SSHAC probability method for assessing earthquake hazards at Swiss nuclear power plants" by Klügel (2005) presents an unusual problem. The paper consists of an extended attack on the methodology and results of a large project (the PEGASOS project, Abrahamson et al 2002) for determining seismic hazard at four Swiss nuclear power plant (NPP) sites. However, the project report from PEGASOS, recently completed, is not at present a public document, nor is there yet a published synopsis of the results as there is for the comparable Yucca Mountain project in the USA (Stepp et al 2001). The reader of Klügel (2005) will thus find many statements about what was done by PEGASOS without any supporting references, and is in the position of being unable to check Klügel's (2005) assertions. Published attacks on unpublished reports are not a normal means of scientific discourse, and we therefore feel a duty to the readership of this journal to present this reply. 
Before proceeding to examine Klügel (2005) in detail, it is perhaps worthwhile to start by considering the matter in hand from the point of view of the history and philosophy of science. We may take the generic case where, on one side, there is a large, wellsupported international project involving a carefully selected team of specialists for a period of some years, and on the other side, a single author of limited resources who disagrees with the findings. It is conceivable that the single author may be correct, if he be endowed with rare insight into the subject under discussion. In the general case, one must admit the possibility that the lone author has found something that the larger team of specialists, suffering from some degree of corporate blindness, has overlooked. The weight of probability, however, is that it is more likely that the lone author has misunderstood the subject. There are well-known historical examples where existing paradigms have been overturned by men of genius, but actually far more examples (much less frequently cited) of authors with unorthodox theories that never had any value whatever.

The relevance of this is not to imply that all challenges to accepted practice are wrong. Rather it is, that in cases of this sort, where the single author wishes to present his case, it is essential that his arguments are clear and cogent, his facts are all correct, and his text is entirely free from technical deficiencies. He has a need to convey to the reader that his criticisms are proceeding from a position of scientific strength, and that his work is of the highest standards of scientific rigour, in order to overcome the fact that the odds of credibility are initially against him. This is all the more the case where a paper is certain to be controversial; it becomes extremely important to ensure that every part of the argument is watertight.

We are therefore surprised to find this degree of care entirely lacking in the case of Klügel (2005). Considering that the PEGASOS project involved 23 experts from two continents, and a high level of technical support for three years, any attempt to overturn the findings would require, as a precondition that such an attempt should 
even be considered, very high standards of scientific argument. Instead, the paper of Klügel (2005) is unclear, poorly argued, ill-informed and frequently incorrect.

A further issue here is the fact that Klügel (2005) is able to analyse and discuss the PEGASOS results - albeit with many erroneous interpretations - because the study was documented in great detail and each decision and assumption was fully justified. In contrast to this, it would be impossible to reproduce the results of Klügel (2005) since he fails to fully document his data, assumptions and calculations, or reference his assertions. Thus few of the calculations performed by Klügel (2005) can actually be checked because of the lack of transparency and the difficulty in following his often convoluted and incomplete descriptions.

\section{Issues of hazard validation}

Klügel (2005) begins with the issue of the validation of hazard results (Section 4). This is certainly an important topic, as argued, for instance, by Musson (2004), a reference cited by Klügel (2005). However, validation can only be against real conditions, and the scope of validation procedures may be constrained depending on what yardsticks are available in any particular case. None of the validation tests presented in Klügel (2005), which are variously termed "validation tests," "sanity checks," and "benchmark tests," are definitive or credible. In fact, Klügel (2005) uses a number of terms (e.g. validation, verification, meaningful, etc.) incorrectly. In particular, Klügel (2005) uses the term "validation" in a way that reflects a lack of appreciation of the principal problems with using this term (this is actually a common problem of usage). The term "verification" is often used synonymously with "validation", indicating that it is possible to determine if the model is "true" or not (e.g., Oreskes et al, 1994). In the empirical (non-axiomatic) sciences, "truth" is essentially a non-scientific term. 


\section{Validation Tests (a), (b), and (c)}

Klügel (2005) introduces six "sanity checks". The first three of these consist of comparisons between the PEGASOS results and three artificial hazard assessments conducted by the author. These are not very clearly explained, but as far as one can follow from the text, Klügel (2005) constructed a source model with only two zones in it, represented these zones as quasi-point sources with normal distributions of distance to the site, assessed parameters for these two zones using firstly, the seismicity of California, secondly, a "maximised" version of the seismicity used by Zwicky et al (1993), and thirdly the PEGASOS catalogue (properly the ECOS catalogue - Earthquake Catalogue of Switzerland, prepared by the Swiss Seismological Service, Zurich) doubled.

These "models of seismicity" are very poorly defined and nearly impossible for the reader to interpret. For example, no citation is given for the California seismicity rate given in Table 1 of Klügel (2005), nor is there a discussion of how this relationship is truncated at the upper magnitude values given. The relative sizes of the regions that have been used to "increase the effective seismic activity" in the Zwicky et al (1993) are not given. How the PEGASOS catalogue was "double-counted" is not defined. The most important recurrence parameter for a source zone is usually the recurrence rate per unit area (e.g., number of events per year per square kilometre), but Klügel's use of point-like sources makes it impossible for the reader to calculate this quantity (only the mean and standard deviation of distance are given) or to compare them with the recurrence rates given for California, the Zwicky et al. region, or the PEGASOS region to be sure that the differences in recurrence are not simply the result of different source sizes.

These three imaginary scenarios are used for hazard calculations using a trio of attenuation equations and the author obtains hazard values in terms of PGA for a 10,000 -year return period varying from $0.08 \mathrm{~g}$ to $0.77 \mathrm{~g}$. Prior to the validation tests, 
a "calibration" test is given in which the California recurrence rate is combined with the Campbell and Bozorgnia (2002) attenuation relationship. It is stated that the mean peak ground acceleration at $10^{-4}$ annual probability of $0.77 \mathrm{~g}$ compares well with the Safe Shutdown Earthquake (SSE) ground motions at California nuclear power plants. Despite the declaration that the SSE hazard level for California nuclear power plants is $10^{-4}$ annual probability, this is not true. The three coastal California plants (Humboldt, Diablo Canyon, and San Onofre) were all designed to SSE values that were assessed deterministically without regard to the mean annual probability of exceedance. Subsequent probabilistic evaluations at these sites, as well as the Rancho Seco site, have shown that the mean annual probability of exceedance varies at these sites. Likewise, compilations of the mean annual probability of exceeding the SSEs at U.S. nuclear power plants show a range of over two orders of magnitude. Hence, Klügel's comparison between his calculated $10^{-4}$ ground motions and the SSEs at California nuclear power plant sites is not a meaningful calibration.

The large range in the calculated values in Table 2 of Klügel (2005) really demonstrates no more than that, if one experiments with changing enough variables in hazard models, one can obtain a variety of hazard values. Comparisons of this nature are not really meaningful and certainly do not count as validation. In this case the comparison is particularly unjustified, because the PEGASOS result quoted includes detailed site response analysis, and the results obtained by Klügel (2005) do not; so one is not comparing like with like.

The results given in Table 2 of Klügel (2005) suffer additionally from odd anomalies, which are neither commented on nor explained by Klügel (2005). In the version where Californian seismicity is transferred to Switzerland, changing the attenuation from Ambraseys and Bommer (1991) to Schwarz and Ende (2004) doubles the 10,000 year PGA, but in the double-ECOS experiment the same change halves it. It 
is hard to see why this should be the case. It is also hard to understand (in the Californian case) how a simple change of attenuation function from Campbell and Borzognia (2002) to Ambraseys and Bommer (1991) should result in such a large change in 10,000 year PGA from $0.77 \mathrm{~g}$ to $0.17 \mathrm{~g}$.

The hazard curves in Figure 1 of Klügel (2005) also look anomalous. Klügel (2005) states that "the aleatory uncertainties (standard deviation for an empirical correlation) in the attenuation laws were used as described by the authors of each correlation and were not truncated or altered in any form". However, the hazard curves presented in Figure 1 have the shape that would be achieved by imposing a truncation on the ground-motion distribution (e.g. Bommer et al, 2004), without which the ground-motion amplitudes would increase considerably for annual exceedance probabilities of less than $10^{-4}$, rather than remaining almost constant as they do in the curves in Klügel's (2005) Figure 1. The shape shown could also be obtained by making the error of treating the aleatory uncertainty (scatter) of the attenuation as if it were epistemic, which would indirectly impose a truncation.

Figure 1 also shows what appear to be the 5-percentile, median, mean, and 95percentile hazard curves, although they are not clearly labelled. These curves differ substantially from each other (i.e., they indicate a high epistemic uncertainty), although these calculations employed only one zonation, one recurrence model (i.e., the California model of Table 1 of Klügel (2005)), and one attenuation equation (i.e., Campbell and Bozorgnia, 2002). Only epistemic uncertainty in maximum magnitude was considered, and this is a small contributor to uncertainty for PGA (see Appendix G of SSHAC, 1997). Also, the mean curve is surprisingly close to the median curve at high amplitudes, given the typical skewness of hazard results (e.g. Abrahamson and Bommer, 2005). These inconsistencies, which are completely unexplained in the text, suggest that there is a problem in the hazard calculations and greatly erode the credibility of these "sanity checks". 
Klügel's (2005) choice of ground motion models is itself curious. This will be discussed in more detail below.

\section{Validation Test (d)}

The fourth "sanity check" involves a comparison between the PEGASOS results and the history of earthquakes in Switzerland, using macroseismic data. In principle, such comparisons can be a very useful tool, correctly applied. The key is to make valid comparisons of like to like. For a site with a reasonably long history of macroseismic observation, one can construct a limited hazard curve (perhaps down to $2 \times 10^{-3}$ annual probability) expressed as intensity. The intensity hazard for the same site can then be computed using the PSHA model, and the two curves compared (Mucciarelli et al 2000, Musson 2005). Deficiencies in the model (for example, unrealistic magnitude-frequency assessments) may be shown up in this way.

It has long been found that the correlation between PGA and intensity is extremely weak, so what one cannot do is convert between PGA and intensity as if it were a deterministic, one-to-one relationship. Unfortunately, this is exactly what Klügel (2005) attempts, using the Californian equation from Murphy and O'Brien (1977) and ignoring the associated uncertainty. The principal result that one should draw from Murphy and O'Brien (1977) is that the scatter around the best-fit formula linking intensity and PGA is so large that the equation itself is not appropriate for practical use. In any case, the equation of Murphy and O'Brien (1977), is out of date; one would expect use to be made instead of the much more recent study by Wald et al. (1999). Moreover, the equation of Murphy and O'Brien (1977) was obtained by regressing values of PGA on values of intensity, as it is presented, and in the Klügel (2005) study it is incorrectly employed to estimate values of intensity from values of PGA. It is noteworthy that Wald et al. (1999) present regressions of intensity on PGA, which could have been employed correctly by Klügel (2005). However, whichever 
relationship one employs, there is enormous scatter associated with such correlations, so great as to make the results of almost no value, and Klügel (2005) ignores this problem entirely.

The gist of Klügel's (2005) argument is that the PEGASOS results predict intensity levels that are as high as those observed during the 1988 Spitak earthquake in Armenia and, since "such an event has never been observed in the near-field of the site considered here," the PEGASOS results do not pass the validation test. Klügel (2005) decides that "an earthquake with a frequency of exceedance of 0.001 " is a meaningful point for comparison and states, without justification, that there is a high level of confidence that such an event would be detected and observed. It is extremely unlikely that any historian would support Klügel's (2005) opinion that the Swiss earthquake catalogue is complete for 2200 years at any magnitude level. In fact, the detailed studies of completeness of the seismicity catalogue given in the PEGASOS report show that the completeness, which varies as a function of location and magnitude, is much shorter than 2200 years for the Swiss region. Nevertheless, Klügel (2005) states that the ground motion associated with 0.001 frequency of exceedance at a particular (not specified) site is $0.29 \mathrm{~g}$ and, after conversion, represents epicentral intensities larger than VIII or IX. He then compares this intensity level to the Spitak earthquake intensities and concludes that, since such intensities have not been observed in the immediate vicinity of the site, either the peak accelerations have been over-predicted or the shape of the hazard spectrum is wrong for Swiss earthquakes. In reality, Klügel (2005) has merely shown that rare events (those with annual frequencies of exceedance of 0.001 ) rarely occur, especially in the "near-field" of a particular site. This is no surprise. By comparison, the recurrence rate for comparable events in active regions shows that they are less rare than for sites in Switzerland. 
In conclusion, therefore, Klügel's (2005) fourth "sanity check" is also without substance.

\section{Validation Tests (e) and (f)}

Klügel's (2005) validation test (e) is based on comparing the uniform hazard spectra from the PEGASOS project with the response spectra of small (magnitude 4) earthquakes recorded at Swiss nuclear power plant sites. Such a comparison cannot be considered a valid "benchmark". Earthquakes of magnitude less than 5 are not of engineering interest since their associated ground motions contain only high frequencies and they are of short duration. Due to these short durations and the absence of low frequencies, such small earthquakes do not generate damage in engineered structures. This point alone explains why the PEGASOS study, in common with standard practice in seismic hazard analysis for nuclear sites, only took into account potential ground motion scenarios of magnitude greater than 5 . The spectra obtained by the PEGASOS study thus reflect the motion of earthquakes with magnitude greater than 5 . Since ground motions from large and small earthquakes do not have the same frequency content, the PEGASOS spectra cannot be compared with motions due to small earthquakes.

For the same physical reason, the use of ground-motion models (Schwarz and Ende, 2004) based mainly on small earthquakes (less than 5) can lead to an underestimation of motion at low frequencies. Moreover, several recent studies (e.g. Ambraseys et al., 2005; Kanamori and Rivera, 2004) have shown that small and large earthquakes could have different stress drops and attenuation characteristics. The dangers of deriving empirical equations from recordings of small-magnitude earthquakes and applying them to predictions for larger events has recently been highlighted by Frisenda et al. (2005). 
It should be noted, however, that the PEGASOS seismicity catalogue does include earthquakes of all magnitudes and the development of earthquake recurrence relationships by the SP1 experts included the rates of occurrence of small-magnitude earthquakes as well as the completeness thresholds of these events.

Klügel (2005) notes that on 28 June 2004 a small earthquake occurred in the vicinity of Baden/Brugg, at a distance of only $6 \mathrm{~km}$ from the nearest power plant. The source of this event was located at a depth of $20 \mathrm{~km}$ and its magnitude is $4.0 \mathrm{ML}$ (3.5 Mw). He then claims that this event represents a case of "characteristic earthquakes" for which "an almost exact return period of 12 years" was observed. Evidence for this claim is not given by Klügel (2005). If one examines the instrumentally recorded seismicity of the last 30 years within a radius of $50 \mathrm{~km}$ from the nearest nuclear power plant in Switzerland, one sees that there were indeed two earthquakes with ML of $3.9(3.7 \mathrm{Mw})$ in 1992 and with 4.7 ML (4.9 Mw) in 1980 (Table 1). Whereas the two events of 1992 and 2004 both occurred in the lower crust of the northern Alpine foreland and thus have some seismotectonic similarity, the event of 1980 was part of an extended earthquake sequence that occurred at mid-crustal depths below the southern Rhine Graben in a significantly different tectonic environment. It is thus obvious that Klügel misunderstood and misused the concept of characteristic earthquakes. In addition, Table 1 shows that in the last 30 years several other earthquakes with magnitudes around 4 also occurred in close proximity to at least one of the nuclear power plants. The claim of an observed 12-year periodicity for the occurrence of characteristic earthquakes in northern Switzerland is thus arbitrary at best. In particular, Klügel (2005) chose to ignore the three earthquakes that occurred between 1987 and 1999 near the town of Fribourg, at a distance of only 21-24 km from the Mühleberg plant. Together with numerous weaker aftershocks, these earthquakes delineate an active $\mathrm{N}-\mathrm{S}$ striking fault in the upper crust that extends over 
a distance of at least $10 \mathrm{~km}$ (Kastrup, 2002) and is therefore easily capable of hosting a magnitude 6 event.

Thus, even without citing the evidence of the 1356 Basel earthquake, which most likely had a magnitude greater than 6.5, the concept proposed by Klügel (2005) of characteristic earthquakes having magnitudes of the order of 3.8 to 4.4 is pure speculation. The source area for these small magnitudes is less than one square kilometre and is simply unimaginable as representing the largest events that a seismic source is capable of generating. One might also question whether Klügel's concept of "temporary characteristic earthquakes" is not self-contradictory.

Test (f) consisted of a PSHA calculation using one of the source models from PEGASOS, but with the attenuation equation of Schwarz and Ende (2004) used for events within $50 \mathrm{~km}$, and Campbell and Borozognia (2002) used for more distant events (despite being derived specifically from data recorded at distances of less than $60 \mathrm{~km}$ ). Details of these calculations are not very clear. In particular, he states that he selected the "mode" source characterisation model "rather than the mean model" - exactly what this means is obscure.

Klügel (2005) found that the uniform hazard spectrum he obtained was a better match to observed spectra from small magnitude earthquakes ("the spectral shape of the resulting uniform hazard spectrum ... matches the empirical observations far better than the PEGASOS results"). The irrelevance of this has already been shown. It is simply not the intention of uniform hazard spectra that they should conform to the spectral shape of local, small magnitude, non-damaging earthquakes. He also notes that his results indicated that the PEGASOS results "over-predict the seismic hazard by a factor of 2 to 3 ". One could equally, and more reliably, draw the conclusion that the results obtained by Klügel (2005) underpredict the hazard by the same amount. In any case, again, since the PEGASOS results include detailed site response analysis and the Klügel (2005) results do not, the comparison is not meaningful. 


\section{Ground motion models}

The aspect of the PEGASOS study that Klügel (2005) directs most attention to is the PEGASOS ground motion (PGM henceforward) model, The usual approach towards empirically justifying or calibrating a model is to bring in new observations and to check if the model is compatible with those data. If such compatibility is not achieved this does not, however, prove that the model is "wrong", which is what Klügel implicitly claims when he repeatedly concludes that the PGM model does not pass a number of his "benchmark tests".

However, if such data existed that could be used to "validate" (in Klügel's use of the term) a model, why would and should such data in that case not be used in the development of the model? The approach and methodology behind the PGM model is based on a systematic search for data and models that could help to constrain the solutions but capture the epistemic uncertainties, and the logic-tree approach is the tool by which such an effort is implemented in a scientifically consistent and transparent way.

Klügel's (2005) approach toward "validating" the PGM model is moreover based on unjustified models, and his arguments hinge in particular very much on weak-motion data and models which require orders-of-magnitude (non-linear) extrapolations. In the PGM documentation this issue is discussed in great detail, with the conclusion that empirical strong-motion data from other regions are more important and reliable for constraining a solution than local weak-motion data. This is not only based on the fact that orders-of-magnitude extrapolations are fundamentally unreliable but also on the fact that large earthquakes are quite similar across different regions if allowances are made for differences in faulting mechanisms, focal depths, stress drop and local sub-surface conditions. 
Klügel (2005) selects three ground-motion prediction equations to use for his "tests" of the PGM. The first of these is the equation of Campbell and Bozorgnia (2002), which Klügel claims "got a rather high rating by the SP2 experts in the PEGASOSproject". This unqualified statement reveals some lack of understanding of what was actually done in the PGM since each SP2 expert assigned different relative weights to the candidate ground-motion models within magnitude-distance bins, and whereas the Campbell and Bozorgnia (2002) equation may have been given a relatively high weighting by some experts at short distances - for which the equation was specifically derived - it was given very low weighting elsewhere. (Note that Klügel in test $\mathrm{f}$ above uses Campbell and Bozorgnia, 2002, for long distances.)

The second of these three equations is the PGA equation of Ambraseys and Bommer (1991), which has long been superseded by Ambraseys (1995) and Ambraseys et al (1996), and most recently by Ambraseys et al (2005). In particular, since Klügel (2005) makes ground motion estimations for a specific site class, it is unclear why he chooses to use Ambraseys and Bommer (1991), which does not include site conditions, when the more recent European equations do explicitly include the site classification as a predictor variable. In order to use the outdated equation to estimate peak acceleration at stiff soil sites, Klügel (2005) applies a factor of 1.17 for scaling motions obtained from Ambraseys and Bommer (1991) to soil conditions, which he attributes to PEGASOS SP2 expert Bommer. However, no such scaling factor was provided in the elicitation summary of this expert - the only time this factor was reported was for transforming PGA estimates from the geometric mean of the horizontal components to the larger of the two horizontal components. On a minor point, it is noted that although Klügel reports the value of 1.17 on p288, on p295 this factor is given as 1.15 .

The third equation is that derived by Schwarz and Ende (2004). The study by Schwarz and Ende (2004) is published only in a university brochure in German, 
rather than having been published in a peer-reviewed journal, which many experts would consider a minimum requirement for a ground-motion model to be used (Cotton et al, 2005). Detailed examination of the Schwarz and Ende (2004) study raises many serious doubts about its applicability to Switzerland. The magnitudes which are used are not calibrated, distance measures are mixed, the frequencydependent regression parameter $h_{0}$, which is usually employed to account for the stabilisation of the regression at close distances, is interpreted as source depth, etc. Furthermore, by including this model, Klügel (2005) contradicts his own objection against taking attenuation relations from other areas, since the Turkish events which it is based on carry all the wave propagation effects from Turkey to Switzerland. This is especially severe for small magnitude earthquakes since those events are of high frequencies, which are especially sensitive to attenuation. Klügel (2005) highlights "the transfer of attenuation laws from other continents to Europe" as a problem in the PGM, but fails to ever address the issue of why ground motions from the Sea of Marmara region are likely to be representative of expected ground motions in Switzerland. The issue of scaling ground motions from small earthquakes to predict the motions from larger events is addressed further later in this discussion.

On this last point it is also important to point out that a large part of the overall PGM produced by SP2 was composed of European models such as Ambraseys et al. (1996), Sabetta and Pugliese (1996) and Berge-Thierry et al. (2003). Neotectonic considerations have been taken into account in the SP2 work. The Alps, the Jura and the Rhine Graben constitute a plate boundary related area, while the Alpine Foreland is an intraplate related area. Large stress drops - and large variations in stress drops - cannot be excluded for Western Central Europe. This in turn called for the use of spectral attenuation relations available for the various ranges of source properties in order to cover the epistemic uncertainty. 
For producing his own "optimal" ground-motion prediction equation, Klügel (2005) chooses a few equations, which he claims "were carefully selected from a wide range of available equations with special emphasis to reflect the effects of near-site earthquakes". This claim cannot be justified. For rock sites he selects the equation of Schwarz and Ende (2004), discussed above (and which is for stiff soil, not rock), and an equation due to Manic (1988). Klügel (2005) does not provide a reference for this latter equation (citing only the review paper by Douglas, 2003), which was presented at the Eleventh European Conference on Earthquake Engineering. The equation, which predicts PGA as a function of surface-wave magnitude, hypocentral distance and site class (rock or soil), was derived using data from the northwest Balkans; here again, Klügel (2005) fails to explain why this equation is applicable to Switzerland. For stiff soil sites, Klügel (2005) adopts three equations: Schwarz and Ende (2004), Ambraseys and Bommer (1991) - adjusted for stiff soil using the mysterious factor discussed earlier - and Ambraseys and Douglas (2000), which should properly have been referenced by the published version, as Ambraseys and Douglas (2003). This latter equation, derived from worldwide data (but dominated by recordings from California) obtained at short source-site distances, shares many of the characteristics of the Campbell and Bozorgnia (2002) equation whose applicability Klügel (2005) questions.

The inappropriate choice of equations, and the way in which they are combined, results in the rock equation at the $95 \%$ confidence level (Table 3 of Klügel, 2005) having a positive value for the coefficient of anelastic attenuation (obviously an impossibility).

In combining different ground-motion prediction equations, Klügel (2005) does not mention the issue of compatibility of the predicted and explanatory variables in the equations, an issue that was given careful attention in developing the PGM (Bommer et al 2003; Scherbaum et al 2004; Bommer et al 2005). Where three ground-motion 
prediction equations are combined, no mention is made regarding the issue of compatibility of the horizontal component: Campbell and Bozorgnia (2002) is based on the geometric mean component, whereas Ambraseys and Bommer (1991) is based on the larger component. The ratio of PGA values obtained using these two different definitions is about 1.17 - the ratio that Klügel (2005) uses to transform siteindependent predictions of PGA to stiff soil sites.

\section{Uncertainties, probabilism and determinism}

A major part of the paper by Klügel (2005) is dedicated to a discussion of uncertainties and some confused arguments that try to demonstrate overestimation of uncertainty in the PEGASOS analyses. Klügel (2005) identifies five different sources of overestimated uncertainty, including the propagation of variability in empirical conversions for magnitude scales and distance metrics, although his own approach is to ignore the incompatibilities that necessitate these adjustments.

Klügel (2005) is critical of the decoupling between source characterisation, attenuation equations, and site-response calculations. It is true that this decoupling may cause some loss of information (i.e. the possibility of somewhat higher aleatory and epistemic uncertainty, particularly the former). However, this potential is wellrecognised and all project participants were made fully aware of the interface between their subproject and the other subprojects. Further, this decoupling is unavoidable given the current state of knowledge about earthquakes and their effects and given that very few (if any) individuals can be considered experts in all these three areas.

Klügel's (2005) critique of the propagation of uncertainty contains a number of errors and incorrect conclusions. In his Equation 3 (and the accompanying text), he claims that in normal PSHA procedure the mean hazard is obtained as the average of the amplitudes for a given exceedence probability over the various branches of the logic 
tree. This is incorrect. It is well known that one computes the mean hazard as the average of the exceedence probabilities for a given amplitude (calculation of the amplitude for a given exceedence probability comes later, after one has computed the complete hazard curve). Chapter 6 of SSHAC (1997) gives more details on this. The choice between these two calculation procedures for the mean hazard curve is not a matter of preference or PSHA tradition. It is firmly rooted in the modern interpretations of probability in risk analysis, where the distinction between aleatory and epistemic uncertainties is ultimately blurred (see, for example, Hartford and Baecher, 2004, and Veneziano, 2003).

In addition, Klügel (2005) claims that his factor $F$ in Equation 3 is a function of the weights, which is not the case. The values of the physical quantities in the logic tree, and the associated weights, are assigned by the experts. This process is conceptually analogous to the process of approximating a continuous distribution by a discrete distribution (e.g., Miller and Rice, 1983) and there is nothing unstable about it. Furthermore, these weights are not random. More importantly, because the values of the physical quantities in the logic tree are not a function of the weights, the MacLaurin expansion in Equation 4 has only one non-zero term (and this term contains the weight raised to a power of zero).

Klügel (2005) makes the claim repeatedly that the PEGASOS approach, as "required" by SSHAC guidance, calls for a separation of aleatory and epistemic uncertainties and that they be treated as "completely uncoupled." Klügel (2005) concludes that this leads to "over estimation" of the uncertainties, since many of the possible combinations of parameters may not be "physically possible." The separation of aleatory variabilities from epistemic uncertainties is, in fact, a part of the SSHAC guidance and a part of modern PSHA methodologies. However, the number of nodes and branches of the logic tree is a function of the complexity of the physical process being modelled and of the associated uncertainty. True, as models for the 
location of future earthquakes and their recurrence rates become more physically realistic (particular for intraplate regions such as Switzerland), there will be more complex logic trees. This does not reflect runaway uncertainties related to treating epistemic and aleatory uncertainties as "completely uncoupled." It is now clearly known that the relationships between aleatory and epistemic components need to be properly represented. To imply that seismic experts construct logic trees with everincreasing numbers of nodes and branches without consideration of the physical reasonableness of the combinations is simply wrong. The PEGASOS documentation of the individual expert assessments, as well as the discussion of the interactions between the various subprojects, confirms the awareness of this issue and the efforts that have been made to deal with it properly.

Therefore, Klügel (2005) is wrong in his conclusion that the final hazard result becomes more diffuse (and may not even converge) as the number of logic-tree branches increases. This mistaken conclusion is the result of a basic misunderstanding on how epistemic uncertainty is treated and propagated in PSHA (Benjamin and Cornell, 1970). If the discrete distributions used to represent epistemic uncertainties are made more fine-grained by introducing additional branches, the final result will be more accurate. Similarly, if the depth of the logic tree is increased as the problem is decomposed into its finer elements, the final result will be more realistic (provided, of course, that the associated logic trees are properly specified and that any correlations between elements are included).

In summary, there is no basis for Klügel's assertions (echoed throughout his paper) that the PEGASOS procedure for uncertainty propagation is somehow unstable, that the uncertainties should be described by a minimal set of parameters, and that more thoroughness by the experts leads to worse hazard results or overestimates the uncertainties. 
Another source of exaggerated uncertainty, according to Klügel (2005), arises from transfer of ground-motion prediction equations from other areas to Central Europe. However, since there are no Swiss models for magnitudes relevant to the PSHA carried out, this is simply unavoidable. How does Klügel (2005) deal with the uncertainty of using recordings from small Turkish earthquakes to moderate Swiss earthquakes? As far as one can infer from his paper, he simply ignores it. Ignoring uncertainties is not the same as reducing uncertainties. While we agree with Klügel's (2005) observation that uncertainty in ground motion has a large effect on the calculated hazard, an observation that has also been noted in other studies (see Stepp et al., 2001, and Appendix I of EPRI, 2003, for recent examples), we do not agree with Klügel's solution of simply ignoring these uncertainties.

Section 6 of Klügel (2005) contains some theoretical discussion of the nature of seismicity that we also take issue with. The discussion of the use of the Poissonian assumption in PSHA presented by Klügel (2005) is superficial. The argument that seismicity is a renewal process and therefore cannot be treated as time-independent is an old one. At the level of individual faults, commonsense suggests that some renewal time between large earthquakes is inevitable. However, it is also true that the collective effect of a number of non-Poissonian processes (e.g. in a seismic source zone) approximates to Poissonian behaviour (Khintchine 1960). Time dependency in seismic hazard is of possible relevance in cases where one is concerned with hazard over very short periods of time (for example, in setting reinsurance premiums for a single year following the occurrence of a large earthquake), but in general, for engineering purposes, treating seismicity as timeinvariant has usually been considered a useful simplification. The work of Cornell and Winterstein (1988) demonstrates that the Poisson assumption leads to only small errors under typical circumstances. 
It is not clear exactly why Klügel (2005) objects that, "Extrapolations based on the Gutenberg-Richter-correlation to infer on possible upper limit magnitudes has no justification" [sic]. Since the Gutenberg-Richter law is not inherently truncated, estimates of maximum magnitudes are not normally based on such extrapolations (presumably what is meant here is extrapolating to some arbitrary low probability level as a definition of maximum event). In fact, in the PEGASOS project a number of different methods were used for estimating upper bound magnitudes, including the use of geological considerations and comparisons with similar tectonic regions.

Klügel (2005) continues, “... it is necessary to conclude that due to the inherent averaging process associated with the use of a stationary model for earthquake recurrence the seismic hazard for a short-lived engineering works in a contemporary low-seismic area is likely to be overestimated strongly". It is hard to follow this argument. The implication is that the use of a non-stationary model would decrease the hazard significantly. This might be the case for a site where hazard was controlled by a single fault that had produced a large earthquake in the recent past, and could be assumed to be in a renewal period for the immediate future. For none of the PEGASOS sites is this really the case. Equally, it is not apparent that anywhere in the PEGASOS study area there is in any sense a large earthquake "overdue". (If there were, then the averaging effect of using a stationary seismicity model would underestimate the immediate hazard; the assertion that assuming a stationary model always overestimates the hazard in low seismicity areas is clearly not the case). Thus the averaging effects of a stationary seismicity model are really quite appropriate in the Swiss case - and, indeed, are particularly likely to be appropriate in low seismicity areas where, in general, it is hard to discern strong links between seismicity and tectonic processes or individual faults.

In the following section of Klügel (2005) alternative approaches to PSHA are discussed. This starts off with the assertion that because of non-ergodicity (by which 
it seems is meant simply that a large earthquake may not be followed immediately by another large earthquake in the same place) earthquake recurrence can only be described using a Bayesian approach. "This naturally limits unjustified extrapolations from observed data to extreme not observed upper limit magnitudes." Once again it is hard to see exactly what is being complained of, and what these "unjustified extrapolations" consist of. Clearly, the possibility of an earthquake occurring in the future larger than any observed in the past cannot be discounted; in fact this is acknowledged by Klügel (2005) in the same paragraph. One can only assume that Klügel (2005) objects to the presumption that the recurrence interval of the maximum earthquake will be the value predicted by extrapolating the Gutenberg-Richter curve. It's possible that the maximum event may not follow the frequency obtained from such an extrapolation; but in the first case one cannot tell whether the frequency will be greater or lesser, and in the second case, the frequency may well be greater, thus increasing the hazard from what would be obtained with a standard GutenbergRichter assumption.

Klügel (2005) argues that earthquakes are not an ergodic process and, therefore, it is unjustified to utilise a stationary stochastic process to represent earthquake occurrences. He provides a long discussion of the conditions for ergodicity of Markov chains and finally presents the existence of aftershocks and foreshocks and characteristic earthquakes as proof of the non-ergodicity of earthquakes. The use of a stationary process with parameters estimated from earthquake catalogues or paleoseismic data is justified by the geological principle of uniformitarianism. We know that changes in the seismotectonic environment are very slow and infrequent; they tend to occur over time scales much longer than the duration of the historical seismicity catalogue and, especially, than the design life of a nuclear facility. Therefore, we are justified in assuming stationarity and using the catalogue to estimate recurrence parameters (within the bounds of uncertainty) for the calculation 
of seismic hazard during the next few decades. In addition, contrary to Klügel's assertion, ergodicity is a common property in stochastic models of earthquakes and in many other physical systems. There are a number of stochastic earthquake models (not necessarily Markovian), that exhibit ergodicity (e.g., Gardner and Knopoff, 1974; Tiampo et al., 2003).

In Section 7, Klügel (2005) continues by proposing a classical deterministic procedure based on assessing the maximum credible earthquake (in other words, exactly the "extreme not observed upper limit magnitude" previously complained of). The case for determinism vs probabilism has been argued very succinctly by McGuire (1999). The essence of the case made by McGuire (1999) is that in instances of very high hazard, the maximum credible earthquake (MCE) has such a high probability of occurring in the lifetime of the structure that one might as well accept the fact and design for it. In instances of low to moderate hazard, the MCE is not very likely to occur in the timeframe of interest, and designing for it is likely to be grossly over-conservative.

This is particularly so in cases like Switzerland where the seismogenic structures are poorly understood. For none of the four NPP sites would one be able to discount the possibility that the MCE might occur at an extremely short distance, with consequent possibility of rather high ground motion. Such an occurrence would be credible; it would not be likely. Hence the desirability of using a probabilistic procedure to avoid unduly pessimistic assessments of the hazard. Conceptually, at least, the deterministic method is far simpler to apply, as Klügel (2005) states, but that does not mean that it is either more realistic or more desirable. In reality and application, the assessment of an MCE is not at all straightforward; nor without considerable uncertainty. As an example, Klügel (2005) presents a formula relating fault rupture length to surface wave magnitude. The PEGASOS experts also considered a number of similar relationships in their assessments of maximum magnitudes. 
However, these relationships require that an assessment be made of the possible lengths of fault ruptures. There are very few known active faults in Switzerland, even in areas of observed seismicity, from which to make inferences about rupture length. An equally important problem - and one that can have even greater consequences for hazard analysis - is that, having decided one way or another on a definition of MCE, in defining an associated ground motion, one comes up against the inherent scatter of predicted PGA values for a given magnitude-distance combination. Should one pick the predicted value plus one standard deviation? Plus two? Plus three? The resulting value is not so much "determined" as arbitrary (Abrahamson, 2000; Bommer, 2003).

Klügel's (2005) recommendation to adopt a deterministic approach for the nuclear power plants in Switzerland is ironic in light of the experience gained in nuclear power plant licensing over the past 20 years in the United States. U.S. regulations originally called for the development of SSE design ground motions using a deterministic approach. Experience gained over the subsequent decade illustrated the difficulties in applying this approach consistently across a variety of tectonic environments. The result was a change in the regulations to require that new nuclear plants perform probabilistic seismic hazard analyses to develop their design SSE (defined as the ground motion with a median $10^{-5}$ annual probability of exceedance). The justification for the change to probabilistic approaches is well documented in the U.S. regulations, and includes the consistency with PRA methodologies and the ability of PSHA to fully incorporate and accommodate uncertainties. Switzerland, as well as other European countries, have demonstrated their foresight in this respect by adopting a probabilistic design approach two decades before the United States did so.

In a final remarkable argument, Klügel (2005) states that he performed a comparative hazard assessment using both the MCE approach and PSHA, using the PEGASOS 
SP1 model for the latter, and obtained similar answers. From this he concludes that the deterministic method produces "very similar results" to the PSHA method without the same complexity (and hence trouble and expense). To generalise from one case study, to the conclusion that the deterministic and probabilistic results are always the same is clearly invalid. So the example proves nothing beyond the circumstances of Klügel's (2005) particular experiment. Secondly, after Klügel (2005) has spent much of the earlier part of the paper arguing that the hazard estimate obtained from PSHA in a low seismicity area "is likely to be overestimated strongly", he now concludes that the MCE approach is a good one because it agrees with the PSHA results. This is not very consistent.

Thus Klügel (2005) is very far from making any sort of convincing argument for preferring a deterministic method over a PSHA one.

Validation is a useful exercise, but it has to be borne in mind that restrictions apply: there are parts of a PSHA study that can be validated, and other parts that cannot. The parts that can reasonably be validated are principally those relating to the earthquake source model (Musson 2000). None of the validation attempts made by Klügel (2005) apply to the parts of the study that could be tested: the seismic source model. In fact, the PEGASOS source model comes in for very little specific criticism. All the tests that he does make are simply comparisons between one set of hazard results and other sets of results involving different assumptions and different procedures, and these cannot be considered as validations.

\section{Conclusions}

Perhaps the most remarkable statement of all occurs in Klügel's (2005) closing paragraph: "Experts shall only be employed in the analysis if it is unavoidable". Normally in science, and in nearly all other aspects of modern life, one prefers expert analysis to inexpert analysis. 
Of course, if highly specialised technical studies are put into the hands of nonexperts, the results are likely to show errors due to misunderstanding of data, misapplication of methods, and all too often, simple mistakes. This is as true of seismic hazard as it is of most other fields.

In the case of the paper of Klügel (2005), this exhibits such a low technical standard that in the normal course of events, a reply would not be worth writing; in fact, one would not normally expect to see such a paper in print in the first place. However, in cases where there is any sort of controversy, it is notorious that erroneous results and conclusions have a habit of propagating and being reproduced out of context; hence a prompt rebuttal is advisable. This is particularly true in the present case, where the reader who is less familiar with earthquake hazard methodology may be inclined to skip through arguments that are hard to follow and go straight to the conclusions. It is for this reason that we have found it necessary to deal with the paper at length.

Finally, seismic hazard is a young discipline, and is still in the situation where the methodology is evolving quite rapidly. The PEGASOS project itself saw a number of methodological developments within the scope of the work, and will doubtless be long remembered by those who took part for the intense and stimulating discussions on the entire range of issues confronting the practice of seismic hazard assessment, that took place throughout the project. We have no doubt that innovations in seismic hazard procedures will continue to be made over the next decades. Debate on methodological issues of seismic hazard in the literature is therefore to be welcomed; but if the debate is to make progress, it is a requirement that contributions should be cogently argued and properly supported by transparent and accurate results. 


\section{Acknowledgements}

The text of this paper has benefited from the comments of other members of the PEGASOS project who are not listed here as authors. This paper is published with the permission of the Executive Director of the British Geological Survey (NERC).

\section{References}

Abrahamson, N.A., (2000). State of the practice of seismic hazard assessment. GeoEng 2000, Melbourne, Australia, 19-24 November, 1, 659-685.

Abrahamson, N.A., Birkhauser, P., Koller, M., Mayer-Rosa, D., Smit, P., Sprecher, C., Tinic S., and Graf, R. (2002). PEGASOS - a comprehensive probabilistic seismic hazard assessment for nuclear power plants in Switzerland. Proceedings of the Twelfth European Conference on Earthquake Engineering, London, Paper no. 633. Abrahamson, N.A. and Bommer, J.J. (2005). Uncertainty and probability in seismic hazard analysis. Earthquake Spectra 21(2), 603-607.

Ambraseys, N.N. (1995). The prediction of earthquake peak ground acceleration in Europe. Earthquake Engineering \& Structural Dynamics, 24, 467-490.

Ambraseys, N.N. and Bommer, J.J., (1991). The attenuation of ground accelerations in Europe. Earthquake Engineering \& Structural Dynamics, 20, 12, 1179-1202. Ambraseys, N.N., Simpson, K.A., and Bommer, J.J., (1996). The prediction of horizontal response spectra in Europe. Earthquake Engineering \& Structural Dynamics, 25, 371-400.

Ambraseys, N.N. and Douglas, J., (2000). Reappraisal of the effect of vertical ground motions on response. ESEE Report No. 00-4, Department of Civil \& Environmental Engineering, Imperial College, London. 
Ambraseys, N.N. and Douglas, J., (2003). Near-field horizontal and vertical earthquake ground motions. Soil Dynamics \& Earthquake Engineering, 23, 1-18. Ambraseys, N.N., Douglas, J., Sarma S.K., and Smit, P.M., (2005). Equations for the estimation of strong ground motions from shallow crustal earthquakes using data from Europe and the Middle East: Horizontal peak ground acceleration and spectral acceleration. Bulletin of Earthquake Engineering, 3(1), 1-53.

Benjamin, J.R. and Cornell, C.A., (1970). Probability, statistics and decision for civil engineers, McGraw-Hill, New York.

Berge-Thierry, C., Cotton, F., Scotti, O., Griot-Pommera, D-A., and Fukushima, Y., (2003). New empirical spectral attenuation laws for moderate European earthquakes. Journal of Earthquake Engineering, 7(2), 193-222.

Bommer, J.J. (2003). Uncertainty about the uncertainty in seismic hazard analysis. Engineering Geology, 70(1/2), 165-168.

Bommer, J.J., Douglas, J., and Strasser, F.O. ,(2003). Style-of-faulting in ground motion prediction equations. Bulletin of Earthquake Engineering, 1(2), 171-203.

Bommer, J.J., Abrahamson, N.A., Strasser, F.O., Pecker, A., Bard, P-Y., Bungum, H., Cotton, F., Faeh, D., Sabetta, F., Scherbaum, F.,.and Studer, J., (2004). The challenge of defining the upper limits on earthquake ground motions. Seismological Research Letters, 70(1), 82-95.

Bommer, J.J., Scherbaum, F., Bungum, H., Cotton, F., Sabetta, F. and Abrahamson N.A., (2005). On the use of logic trees for ground-motion prediction equations in seismic hazard assessment. Bulletin of the Seismological Society of America, 95(2), 377-389.

Campbell, K.W. and Bozorgnia, Y., (2003). Updated near-source ground motion relations for horizontal and vertical components of peak ground acceleration and 
acceleration response spectra. Bulletin of the Seismological Society of America, 93(1), 314-331.

Cornell, C.A. and Winterstein, S.R., (1988). Temporal and magnitude dependence in earthquake recurrence mModels, Bulletin of the Seismological Society of America, 78, 1522-1537.

Cotton, F., Scherbaum, F., Bommer J.J., and Bungum, H., (2005). Criteria for selecting and adjusting ground-motion models for specific target applications: applications to Central Europe and rock sites. Journal of Seismology, submitted. Douglas, J. (2003). Earthquake ground motion estimation using strong-motion records: a review of equations for the estimation of peak ground acceleration and response spectral ordinates. Earth Science Reviews 61, 43-104.

EPRI (2003). Scientific and technical priorities at Yucca Mountain. Palo Alto, EPRI TR-1003335.

Frisenda, M., Massa, M., Spallrossa, D., Ferreti, G. and Eva C. (2005). Attenuation relationship for low magnitude earthquakes using standard seismometric records. Journal of Earthquake Engineering, 9(1), 23-40.

Gardner, J. K., and Knopoff, L., (1974). Is the sequence of earthquakes in southern California, with aftershocks removed, Poissonian? Bulletin of the Seismological Society of America, 64(5), 1363-1367.

Hartford, D. N. D, and Baecher, G.B., (2004), Risk and Uncertainty in Dam Safety, Thomas Telford Ltd., London.

Kanamori, H. and Rivera, L., (2004). Static and dynamic scaling relations for earthquakes and their implication for rupture speed and stress drop. Bulletin of the Seismological Society of America, 94, 314-319. 
Kastrup, U. (2002). Seismotectonics and stress field variations in Switzerland. PhD. Thesis ETHZno 14527. 153 p.

Khintchine, A.J., (1960). Mathematical models in the theory of queuing, Griffin, London.

Klügel, J-U., (2005). Problems in the application of the SSHAC probability method for assessing earthquake hazards at Swiss nuclear power plants. Engineering Geology, 78, 285-307.

McGuire, R.K. (1999) Deterministic vs probabilistic earthquake hazards and risks, Soil Dynamics and Earthquake Engineering, 21, 377-84.

Manic, M.I. (1988). A new site dependent attenuation model for prediction of peak horizontal acceleration in Northwestern Balkan. Proceedings of the Eleventh European Conference on Earthquake Engineering, Paris.

Miller, A.C. and Rice, T.R. (1983). Discrete approximations of probability distributions. Management Science, 29, 352-362.

Mucciarelli, M., L. Peruzza and P. Caroli (2000). Tuning of seismic hazard estimates by means of observed site intensities, Journal of Earthquake Engineering, 4, 141-59.

Murphy, J.R. and L.J. O'Brien (1977). The correlation of peak ground acceleration amplitude with seismic intensity and other physical parameters, Bulletin of the Seismological Society of America, 67, 3, 877-915.

Musson, R.M.W. (2000). Evaluation of seismic hazard source models. In J. Lapajne and R. Vidrih (eds.), Seismicity modelling in seismic hazard mapping. Ljubljana: Slovenian Geophysical Survey.

Musson, R.M.W. (2004). Objective validation of seismic hazard source models. In Proceedings of 13th World Conference on Earthquake Engineering. Vancouver. 
Musson, R.M.W. (2005) Intensity attenuation in the UK, Journal of Seismology, 9, 1, 73-86.

Oreskes, N., Shrader-Frechette K., and Belotz, K. (1994). Verification, validation and confirmation of numerical models in the earth sciences. Science, 263, 641-646.

Sabetta, F. and Pugliese, A., (1996). Estimation of response spectra and simulation of nonstationary earthquake ground motions. Bulletin of the Seismological Society of America, 86(2), 337-352.

Scherbaum, F., Schmedes, J. and Cotton, F., (2004). On the conversion of sourceto-site distance measures for extended earthquake source models. Bulletin of the Seismological Society of America, 94(3),1053-1069.

Schwarz, J., and Ende, C., (2004). Spektrale Abnahmebeziehungen zur Bestimmung seismischer Bemessungsgrössen auf Grundlage von Starkbebenregistrierungen in der Türkei. Seismische Gefährdungsberechnung und Einwirkungsbeschreibung, Schriften der Bauhaus-Universität Weimar, 116, 91-104.

Senior Seismic Hazards Analysis Committee (1997). Recommendations for probabilistic seismic hazard analysis: Guidance on uncertainty and the use of experts, NUREG/CR6372, Nuclear Regulatory Commission, Washington, 256 p. Stepp, J.C., I. Wong, J. Whitney, R. Quittmeyer, N.A. Abrahamson, G.R. Toro, R. Youngs, K.J. Coppersmith, J. Savy, T. Sullivan and Yucca Mountain PSHA Project Members (2001). Probabilistic seismic hazard analyses for ground motions and fault displacement at Yucca Mountain, Nevada, Earthquake Spectra, 17, 113-52.

Tiampo, K. F., Rundle, J. B., Klein, W., Sá Martins, J. S. and Ferguson C. D. (2003). Ergodic Dynamics in a Natural Threshold System. Physical Review Letters, 91, 238501.

Veneziano, D. (2003). Uncertainty and Decision under Uncertainty. Chapter 2 of Y. K. Wen, B. R. Ellingwood, D. Veneziano, and J. Bracci, Uncertainty Modeling in 
Earthquake Engineering, Mid-America Earthquake Center, MAE Center Project FD-2 Report, February 12.

Wald, D.J., Quitoriano, V., Heaton T.H. and Kanamori, H., (1999). Relationships between peak ground acceleration, peak ground velocity, and Modified Mercalli intensity in California. Earthquake Spectra, 15(3), 557-564.

Zwicky, P., J.-C. Griesser and Rast, B., (1993). Vergleich der Erdbebengefährdung an den Standorten der schweizerischen Kernkraftwerke. Report \#1929-2, by Basler \& Hofmann Consulting Engineers, prepared for the Swiss Federal Office of Energy and the Swiss Federal Nuclear Safety Inspectorate. 


\section{Tables}

Date Time Lat Lon $h$ Mw ML Location and distance to nearest plant

\begin{tabular}{|c|c|c|c|c|c|c|c|c|c|c|c|c|c|c|}
\hline 1979 & 07 & 03 & 21 & 13 & 46.930 & 7.038 & 28 & 3.6 & 3.8 & Murten & (18 & $\mathrm{km}$ & from & n Mühleberg) \\
\hline 1980 & 07 & 15 & 12 & 17 & 47.628 & 7.518 & 15 & 4.9 & 4.7 & Sierentz & $(45$ & $\mathrm{km}$ & from & Gösgen) \\
\hline 1980 & 07 & 16 & 15 & 00 & 47.653 & 7.503 & 17 & 3.8 & 4.0 & Sierentz & $(47$ & $\mathrm{km}$ & from & Gösgen) \\
\hline 1984 & 09 & 05 & 05 & 16 & 47.247 & 8.562 & 15 & 3.8 & 4.0 & Albis & $(42$ & $\mathrm{km}$ & from & Beznau) \\
\hline 1987 & 09 & 20 & 11 & 53 & 46.758 & 7.215 & 7 & 3.7 & 3.9 & Fribourg & $(24$ & $\mathrm{km}$ & from & Mühleberg) \\
\hline 1987 & 12 & 11 & 02 & 25 & 47.314 & 7.163 & 9 & 3.5 & 3.7 & Glovelier & (39 & $\mathrm{km}$ & from & Mühleberg) \\
\hline 1992 & 12 & 30 & 21 & 34 & 47.717 & 8.370 & 25 & 3.7 & 3.9 & Wutöschingen & $(21$ & $\mathrm{km}$ & from & Beznau) \\
\hline 1995 & 09 & 17 & 16 & 29 & 46.781 & 7.184 & 7 & 3.5 & 3.7 & Fribourg & $(22$ & $\mathrm{km}$ & from & Mühleberg) \\
\hline 1999 & 02 & 14 & 05 & 57 & 46.782 & 7.212 & 7 & 4.0 & 4.3 & Fribourg & $(21$ & $\mathrm{km}$ & from & Mühleberg) \\
\hline 2004 & 06 & 28 & 23 & 42 & 47.525 & 8.169 & 20 & 3.5 & 4.0 & Brugg & $(6$ & $\mathrm{km}$ & from & Beznau) \\
\hline 2005 & 05 & 12 & 01 & 38 & 47.264 & 7.651 & 25 & 3.7 & 4.1 & Balsthal & $(27$ & $\mathrm{km}$ & from & Gösgen) \\
\hline
\end{tabular}

Table1: All earthquakes since 1975 with $\mathrm{Mw}>=3.5$ within a distance of $50 \mathrm{~km}$ from at least one of the Swiss nuclear power plants. 